\section{PERENCANAAN PERLINDUNGAN DAN PERBAIKAN PANTAI DESA BANYUSANGKA KECAMATANTANJUNGBUMI \\ KABUPATEN BANGKALAN MADURA}

\section{Hari Eko Meiyanto}

Staf Pengajar Jurusan Teknik Sipil

Kampus III, Jl. Raya Tlogomas No. 246

\section{ABSTRACT}

A protection and an improvement of shore is essentially if the shorelines setback cause of the surf hiting and moreever at the beach areas there are settlements or an important buildings. The plans of the shore protection building is consist of several parameters, including: wind, fetch and wave. The shore protection buildings be able to protect the coast from the blow of the waves and it's should also be able to withstand the loads around the building. As for the planned the materia protective buildings are use stone, which is called revetment. The dimensions of the planned revetmen are : a top elevation $+4.00 \mathrm{~m}$, width $1.5 \mathrm{~m}$ with two layers of protection and toe protection. Two protective layers are the primar layers and secondar layers, the primer thick layers is 1.0 meters and the secondar thick layers is 0.5 meters, the primar protective stone weight is 0.18 tonnes and 0.018 tonnes for second

Keyword : The shore protection buildings

\section{PENDAHULUAN}

Kabupaten Bangkalan tepatnya di desa Banyusangka Kecamatan Tanjung Bumi berada di pulau Madura. Sepanjang pantai desa Banyusangka terjadi kerusakan yang diakibatkan oleh hantaman ombak, sehingga warga sekitar mengadakan penanggulangan terhadap ombak tersebut dengan membuat tumpukan batu semacam breakwater di sebelah timur tetapi pengadaan penanggulangan tersebut tidak menggunakan analisa yang tepat dan sesuai sehingga mengakibatkan kerusakan daerah pantai sebelah barat. antara 2-8 meter dari permukaan laut rata-rata, dengan kondisi pada sebagian besar wilayahnya adalah berupa daratan dengan kemiringan tanah antara $0-2 \%$ dan

\section{METODOLOGI PENELITIAN}

Data angin diperoleh dari hasil pengukuran yang dilakukan oleh Badan Meteorologi Klimatologi dan Geofisika (BMKG) Maritim Perak Surabaya di daratan yang kemudian ditransformasikan dari data kondisi lapangan.
Fakultas Teknik - Univ. Muhammadiyah Malan

Desa Banyusangka berada pada ketinggian suhu udara antara $25^{\circ}-32^{\circ} \mathrm{C}$.

\section{HASIL DAN PEMBAHASAN}

Pengumpulan Data

Pengukuran dilakukan untuk peta bathimetr sampai pada kedalaman 10 meter dan didapat kemiringan dasar laut $m=0.02(1: 50)$. Fetch yan didapat dari data yaitu $105.09 \mathrm{~km}$. Kecepatan angi maksimum $17.65 \mathrm{knot}(9.07 \mathrm{~m} / \mathrm{d})$ dari arah barat $\left(247.5^{\circ}-292.5^{\circ}\right)$. Tinggi gelombang maksimum yang erjadi $0.64 \mathrm{~m}$ dari arah barat $\left(2475^{\circ}-292.5^{\circ}\right)$. (a) Bebcrapa evasi malr Level $)=+2.00 \mathrm{~m}, \mathrm{LWL}($ Low Water Level $)= \pm 0.0$ $\mathrm{m}, \operatorname{MSL}($ Mean Sea Level $)=+0.88 \mathrm{~m}$.

\section{Perencanaan Struktur}

a. Elevasi Puncak Rencan

Elevasi muka air laut rencana di dasarkan pad analisa HWL $($ High Water Level $)=(+2.00) \mathrm{m}$, wave setup $(\mathrm{Sw})=0.06 \mathrm{~m}$, wind setup $(\ddot{\mathrm{Äh}})=0.02 \mathrm{~m}$ pemanasan global (Sea Level Rise $)=0.3 \mathrm{~m}$, sehingga didapat elevasi muka air laut rencana $(\mathrm{DWL})=+2.38$ m. Elevasi puncak revetment didapat dari elevasi muka air laut rencana $(\mathrm{DWL})=+2.38 \mathrm{~m}$, runup gelombang $(\mathrm{Ru})=1.23 \mathrm{~m}$, tinggi jagaan $(\mathrm{tj})=0.5 \mathrm{~m}$, sehingga didapat elevasi puncak revetment $=+4.0 \mathrm{~m}$.

b. Desain Revetment

Revetment adalah bangunan dari tumpukan bat yang bagian luarnya diberi lapis pelindung yang terbua dari batu. Konstruksi revetment direncanakan terdiri dari tiga bagian yaitu lapisan primer, sekunder da pelindung kaki.

\section{Tabel 1. Stabilitas Revetment dan Concrete Tidal Wall} Untuk mendapatkan mawar gelombang (waverose) menggunakan program WRPlot.

Data pasang surut, peta bathimetri, fetch dan data tanah didapat dari Dinas Kelautan dan Perikanan Kabupaten Bangkalan. Dari beberapa data yang didapat dilakukan analisa perhitungan sehingga didapat perencanaan bangunan pelindung yang sesuai dengan

10 |Media Teknik Sipil, Volume 10, Nomor 1, Februari 2012: 10 - 13
Lapisan primer direncanakan dengan berat butir lapis pelindung $(\mathrm{W}): 0.18$ ton, lebar puncak revetment $(\mathrm{B}): 1.5 \mathrm{~m}$, tebal lapis pelindung (t $\left.{ }^{2}\right)$ : $1.0 \mathrm{~m} . \mathrm{Lapisan}$ sekunder direncanakan denganberat butir lapis pelindung $(\mathrm{W}, 0.018$ ton, tebal lapis pelindung $\left(\mathrm{t}_{\text {sekunder }}\right): 0.5 \mathrm{~m}$. Pelindung kaki direncanakan dengan lebar pelindung kaki $\left(\mathrm{B}_{1}\right)=2.0$ $\mathrm{m}$ dan $\left(\mathrm{B}_{2}\right)=1.0 \mathrm{~m}$, tebal lapis pelindung $\mathrm{kaki}=(\mathrm{t})=$ $1.5 \mathrm{~m}$, berat batu pelindung kaki $=\left(\mathrm{W}_{\text {primes }}\right)=0.18$

Pemakaian sisi tegak diperlukan perlindungan di dasar bangunan yang berupa batu untuk mencegah erosi. Untuk mencegah keluarnya butiran tanah halus melalui sela - sela batuan yang dapat berakibat terjadinya penurunan bangunan, pada dasar pondasi diberi lapis geotekstil. Desain concrete tidal wall yang direncanakan yaitu dengan tebal puncak $(b)=0.60 \mathrm{~m}$, kedalaman $(\mathrm{D})=\mathrm{H} / 8=4.15 / 8=0.52 \mathrm{~m}$, lebar $\left(\mathrm{B}_{2}\right)=$ $\mathrm{D} / 2=0.52 / 2=0.26 \mathrm{~m}$, lebar alas $\left(\mathrm{B}_{1}\right)=0.7 \mathrm{H}=0.7 \times$ $4.15=2.90 \mathrm{~m}$, lebar $\left(\mathrm{B}_{3}\right)=0.80 \mathrm{~m}$.

\section{Pembahasan}

Dalam perencanaan dinding pantai perlu ditinjau fungsi dan bentuk bangunan, lokasi, panjang, tinggi, stabilitas bangunan dan tanah pondasi, dan sebagainya Pada kemiringan garis pantai yang d" $45^{\circ}$ menggunakan bangunan pelindung pantai revetment dan pada kemiringan garis pantai yang $45^{\circ}>$ á d" $90^{\circ}$ menggunakan bangunan pelindung pantai concrete tidal wall (tembok laut). Pada daerah pembangunan pelindung pantai tidak digunakan untuk menambat perahu - perahu karena kedalaman air yang tidak dapat digunakan untuk menambat. Berdasarkan beberapa kreteria maka digunakan bangunan pelindung revetment.

Hari Eko Meiyanto, Perencanaan Perlindungan Dan Perbaikan Pantai Desa Banyusangkal 11 Kecamatan Tanjungbumi Kabupaten Bangkalan Madura 


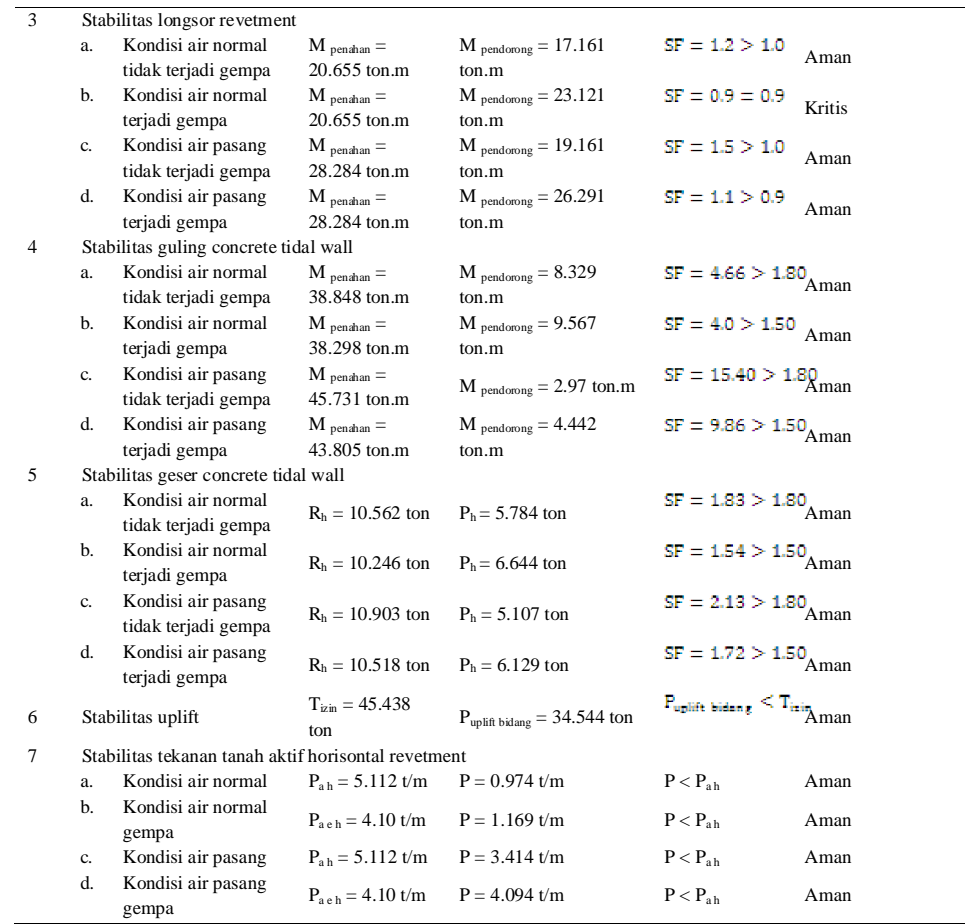

\section{KESIMPULAN DAN SARAN}

\section{Kesimpulan}

Bangunan pelindung yang digunakan adalah revetment. Tinggi gelombang signifikan $\left(\mathrm{H}_{\mathrm{s}}\right)=1.024$ $\mathrm{m}$, Desain Water Level $(\mathrm{DWL})=2.38 \mathrm{~m}$. Elevasi puncak rencana revetment $=+4.00 \mathrm{~m}$, lebar puncak revetment $(\mathrm{B})=1.5 \mathrm{~m}$ dengan dua lapis pelindung dan pelindung kaki. Dua lapis pelindung yaitu lapisan primer dan sekunder, berat batu primer $\left(\mathrm{W}_{\text {pire }}\right)=0.18$ ton dengan tebal $\left(\mathrm{t}_{\text {primer }}\right)=1.0 \mathrm{~m}$ dan berat batu sekunder $\left(\mathrm{W}_{\text {seknuder }}\right)=0.018$ ton dengan tebal $\left(\mathrm{t}_{\text {sekunde }}\right)$

$=0.5 \mathrm{~m}$. Kemiringan rencana revetment $=45^{\circ} \mathrm{Lebar}$ pelindung $\operatorname{kaki}\left(\mathrm{B}_{\mathrm{f}}\right)=2.0 \mathrm{~m}$ dan $\left(\mathrm{B}_{2}\right)=1.0 \mathrm{~m}$, tebal lapis pelindung $\mathrm{kaki}=(\mathrm{t})=1.5 \mathrm{~m}$, berat batu pelindung kaki $=\left(\mathrm{W}_{\text {primer }}\right)=0.18$ ton. Digunakan geotekstil dengan AOS (Apparent Opening Size) atau ukuran bukaan geotekstil d" $2.375 \mathrm{~mm}$.
Saran

Perencanaan bangunan pelindung pantai menjad sangat penting apabila daerah pantai mulai rusak karena hantaman gelombang yang terus meneru sehingga garis pantai mengalami kemunduran. Daerah pantai yang sudah mulai rusak harus segera dibangu pelindung pantai sebelum terjadi kerusakan yang lebih parah. Apalagi kalau daerah pantai tersebut terdapat bangunan penting dan atau daerah pemukiman penduduk.

\section{DAFTAR PUSTAKA}

Bowles. Analisis Dan Desain Pondasi. Terjemahan oleh: Silaban, 1993. Penerbit Erlangga. Jakarta.

Hardiyatmo. 2010. Analisa Dan Perancangan Fondasi (Bagian 1). Gadjah Mada University Press. Yogyakarta.
Kusuma. I. 2008. Studi Perencanaan Pemeca Gelombang Pelabuhan Pangkalan TN Angkatan Laut di Desa Karangwuni Kabupaten Kulonprogo. Universitas Gadjah Mada. Yogyakarta.

Nakazawa. Mekanika Tanah dan Teknik Pondasi. Terjemahan oleh : Sosrodarsono. 1994. PT Pradnya Paramita. Jakarta.

Soedarmo. D. \& Purnomo. E. 1993. Mekanika Tanah. Penerbit Kanisius. Yogyakarta.

Triatmodjo. B. 1996. Pelabuhan. Beta Offset. Yogyakarta

Triatmodjo. B. 1999. Teknik Pantai. Beta Offset. Yogyakarta

12 |Media Teknik Sipil, Volume 10, Nomor 1, Februari 2012: 10 - 13

Hari Eko Meiyanto, Perencanaan Perlindungan Dan Perbaikan Pantai Desa Banyusangkal 13 Kecamatan Tanjungbumi Kabupaten Bangkalan Madura 